\title{
Eye Diseases among Women Engaged in Local Extraction of Palm Kernel Oil in the Kumasi Metropolis
}

\author{
David Ben Kumah, ${ }^{1}$ Samuel Aikins, ${ }^{2}$ Abigail Owusu Ansah, \\ Kwadwo Owusu Akuffo, ${ }^{1}$ and Eugene Appenteng Osae ${ }^{1}$ \\ ${ }^{1}$ Department of Optometry and Visual Science, College of Science, Kwame Nkrumah University of Science and Technology, \\ Kumasi, Ghana \\ ${ }^{2}$ Department of Theoretical and Applied Biology, College of Science, Kwame Nkrumah University of Science and Technology, \\ Kumasi, Ghana
}

Correspondence should be addressed to David Ben Kumah; ben56kay@gmail.com

Received 1 July 2014; Revised 12 September 2014; Accepted 27 September 2014; Published 13 October 2014

Academic Editor: Leo J. Schouten

Copyright (C) 2014 David Ben Kumah et al. This is an open access article distributed under the Creative Commons Attribution License, which permits unrestricted use, distribution, and reproduction in any medium, provided the original work is properly cited.

The study aimed to determine the prevalence of eye diseases among women engaged in the local extraction of palm kernel oil in the Kumasi Metropolis. A cross-sectional study was carried out in five women groups purposively sampled. A total of 150 women were sampled. History taken from the women included participants' demographics and ocular and occupational history. Ocular examination included visual acuity and ophthalmoscopy. The Statistical Package for Social Sciences (SPSS) version 17.0 was used to analyze the data. Descriptive statistics and Chi-square test were employed. A total of 150 women aged from 17 to 84 years were examined. The prevalence of eye diseases was $56.0 \%$. The ocular disease with the highest prevalence was pterygium (34.0\%), followed by cataract and pinguecula ( $20.0 \%$ each). The study revealed a high ocular morbidity rate. Regular eye examination and education are recommended for these women since they are exposed to several risk factors which play important roles in ocular morbidities.

\section{Introduction}

Occupational hazards are dangers associated with human health and well-being inherent primarily in people's occupations [1]. Workers may be exposed to toxins, dust, ionizing and nonionizing radiations, extreme heat, and chemicals like lead, mercury, carbon monoxide, and other organic solvents [2].

In Ghana, an appreciable number of persons working in a variety of indigenous industries, namely, fishing, blacksmithing, making of ornaments, farming, and palm kernel oil production, are also exposed to the majority of these hazards [3].

The processing and production of palm kernel oil using indigenous methods exist mainly at household levels in most Ghanaian communities, even though a few small scale manufacturing industries and cooperatives have also joined the production of the oil [3].
In a study done on traditional palm kernel oil production in Cape Coast [4] by Anang and Boadu, (2013) statistics showed that the majority of the workers in the palm kernel oil production were women who as a result of their operations were exposed to intense fire source, smoke, sharp flying objects such as nut shells, oil splashes, and spills that resulted in cuts and burns, and possibly other injuries of varying degrees.

The Health and Safety Executive (2005) reported that 1.5 million workers in all industries suffered ill health caused or made worse by work [5]. This statistic could be a true reflection of the case of kernel oil production workers locally. The workers work in poor, untidy, smoky, and sunny environments and with little or no adherence to proper ergonomics. Squatting, prolonged standing, and bending cause them abdominal pains, sleeping disorders, breathing difficulties, fatigue, and general body aches [4]. Harmful agents such as hydrogen sulfide, which is a component of smoke from 
different sources, are said to cause eye irritations and excite conditions such as allergic conjunctivitis [6].

There are other several eye conditions that they could also be exposed to. According to Khurana, (2007), people working in high temperature, smoky and dusty environments are likely to suffer conditions such as pterygium, dry eyes, pingueculum, and some acquired forms of cataract [7]. It will suffice to say that workers who work without any form of facial protection are highly at risk of developing these disease conditions.

This study attempted to determine the eye diseases prevalent among women engaged in the local extraction of palm kernel oil in the Kumasi Metropolis.

\section{Methods}

2.1. Study Population. A descriptive cross-sectional study was carried out in the Kumasi Metropolis in the Ashanti region of Ghana. The study population for this study included all women engaged in local extraction of palm kernel oil.

2.2. Sampling. Five women groups engaged in the extraction were purposively sampled to participate in the study. A total of 150 women engaged in the extraction were sampled.

2.3. Data Collection Technique. Interviewer administered questionnaires were filled detailing demographic profile of study subjects and occupational history. A thorough eye examination was carried out on all the local women. Distance visual acuity was taken using the Snellen Chart at 6 metres and ophthalmoscopy was carried out using the Welch Allyn direct ophthalmoscope. All women engaged in local extraction of palm kernel oil present at the time of the study visit were included in the study.

2.4. Data Analysis. The Statistical Package for Social Sciences (SPSS) software, version 17.0, was used to analyze the collected data. The tool employed was descriptive statistics, and Chisquare test was used to find out significant differences between comparable categorical groups.

2.5. Ethical Consideration. Informed consent of the women was first sought through direct interaction. Participants were also assured of the confidentiality of the information gathered.

\section{Results}

A total of 150 respondents were examined. These respondents were all women with an age range of $17-84$ years. The modal age range was $45-54$ years. Table 1 shows the age composition of the respondents.

3.1. History of Respondents. A considerable number of the study participants were illiterates with a frequency of $66.7 \%$. The frequency of literates was $33.3 \%$. The respondents also self-reported information about their personal disease states;
TABLE 1: Age distribution of the respondents.

\begin{tabular}{lc}
\hline Age range (years) & Frequency $(\%)$ \\
\hline $17-24$ & $19(12.7 \%)$ \\
$25-34$ & $17(11.3 \%)$ \\
$35-44$ & $34(22.7 \%)$ \\
$45-54$ & $38(25.3 \%)$ \\
$55-64$ & $25(16.7 \%)$ \\
$65-74$ & $15(10.0 \%)$ \\
$75-84$ & $2(1.3 \%)$ \\
\hline Total & $150(100 \%)$ \\
\hline
\end{tabular}

TABLE 2: Distribution of years of experience in business.

\begin{tabular}{lc}
\hline Number of years in business & Frequency (\%) \\
\hline $1-5$ & $37(24.7 \%)$ \\
$6-10$ & $35(33.3 \%)$ \\
$11-15$ & $31(20.7 \%)$ \\
$>15$ & $47(31.3 \%)$ \\
\hline Total & $150(100 \%)$ \\
\hline
\end{tabular}

medical conditions like diabetes, hypertension, asthma, and many others had a frequency of $38.0 \%$. Other conditions such as tuberculosis, malaria, and pulmonary diseases had a frequency of $26.7 \%$.

The frequency of respondents with no known ocular history or those who were not aware of the state of their eye health was $78.7 \%$. There was $77.2 \%$ frequency value for the respondents who reported being unaware of any family ocular history. The frequency for those who reported a history of blindness in their family was $8.7 \%$ and $3.3 \%$ of the respondents reported having had an eye surgery.

3.2. Experience in Business. Respondents who have spent more years in the business ( 15 years and above) are the most experienced, followed by respondents who have 11-15 years in the business, with the least number of years being 1-5 years. Table 2 shows the distribution of respondents' experience in the business.

All the respondents had one or more ocular symptoms. The ocular symptom with the highest prevalence among the respondents was tearing (73.3\%); dizziness was the least reported symptom $(0.7 \%)$. The reported symptoms per duration of respondents in business are summarized in Table 3.

3.3. Visual Status of Respondents. The majority (>80.0\%) of the respondents had visual acuities of $6 / 12$ and better, while a few of the respondents $(<10.0 \%)$ had visual acuities worse than 6/18; some $(74.0 \%)$ of these respondents had cataracts, pterygium, and pingueculum. Normal visual acuity was marked at 6/5-6/9 using the Snellen chart. Table 4 summarizes the visual status of the respondents.

3.4. Prevalence of Ocular Conditions. Eye examinations showed that the total number of respondents with ocular conditions was eighty four, giving a prevalence of $56.0 \%$. 
TABLE 3: Cross tabulation of presenting ocular symptoms with duration in business.

\begin{tabular}{|c|c|c|c|c|c|}
\hline \multirow{2}{*}{ Ocular symptoms } & \multicolumn{4}{|c|}{ Frequency per duration in business (years) } & \multirow{2}{*}{$\begin{array}{c}\text { Total } \\
N=150\end{array}$} \\
\hline & $1-5(n=37)$ & $6-10(n=35)$ & $11-15(n=31)$ & $>15(n=47)$ & \\
\hline Tearing & $33(89.2 \%)$ & $32(91.4 \%)$ & $25(80.6 \%)$ & $20(42.5 \%)$ & $110(73.3 \%)$ \\
\hline Pain & $10(27.0 \%)$ & $10(28.6 \%)$ & $8(25.8 \%)$ & $24(51.1 \%)$ & $52(34.7 \%)$ \\
\hline Itching & $30(81.1 \%)$ & $28(80.0 \%)$ & $16(51.6 \%)$ & $26(55.3 \%)$ & $100(66.7 \%)$ \\
\hline Discharge & $6(16.2 \%)$ & $6(17.1 \%)$ & $5(16.1 \%)$ & $5(10.6 \%)$ & $22(14.7 \%)$ \\
\hline Headache & $14(37.8 \%)$ & $12(34.3 \%)$ & $6(19.4 \%)$ & $20(42.5 \%)$ & $52(34.7 \%)$ \\
\hline Photophobia & $7(18.9 \%)$ & $10(28.6 \%)$ & $7(22.6 \%)$ & $9(19.1 \%)$ & $33(22.0 \%)$ \\
\hline Halos & $1(2.7 \%)$ & $1(2.9 \%)$ & $2(6.4 \%)$ & $8(17.0 \%)$ & $12(8.0 \%)$ \\
\hline Blurred vision & $9(24.3 \%)$ & $7(20.0 \%)$ & $15(48.4 \%)$ & $24(51.1 .6 \%)$ & $55(36.7 \%)$ \\
\hline Double vision & $4(10.8 \%)$ & $4(11.4 \%)$ & $4(12.9 \%)$ & $7(14.9 \%)$ & $19(12.7 \%)$ \\
\hline Dizziness & - & - & - & $1(2.1 \%)$ & $1(0.7 \%)$ \\
\hline Foreign body sensation & $2(5.4 \%)$ & - & $2(6.4 \%)$ & - & $4(2.7 \%)$ \\
\hline
\end{tabular}

TABLE 4: Visual status of the respondents.

\begin{tabular}{lcc}
\hline Entrance visual acuity & Right eye & Left eye \\
\hline $6 / 5-6 / 9$ & $123(82.0 \%)$ & $116(77.3 \%)$ \\
$6 / 12-6 / 18$ & $13(8.7 \%)$ & $19(12.7 \%)$ \\
$6 / 24-6 / 36$ & $12(8.0 \%)$ & $11(7.3 \%)$ \\
$6 / 60$ and worse & $2(1.3 \%)$ & $4(2.7 \%)$ \\
\hline Total & $150(100 \%)$ & $150(100 \%)$ \\
\hline
\end{tabular}

TABLE 5: Prevalence and distribution of eye conditions per years of experience in business.

\begin{tabular}{lcc}
\hline Ocular conditions & \multicolumn{2}{c}{ Number affected $(N=150)$} \\
Frequency & Percentage \\
\hline Ectropion & 1 & $0.67 \%$ \\
Entropion & 1 & $0.67 \%$ \\
RAPD & 1 & $0.67 \%$ \\
Corneal scar & 2 & $1.33 \%$ \\
Hazy vitreous & 3 & $2.00 \%$ \\
Macular degeneration & 4 & $2.67 \%$ \\
Ptosis & 4 & $2.67 \%$ \\
Glaucoma suspect & 8 & $5.33 \%$ \\
Conjunctivitis & 10 & $6.675 \%$ \\
Cataract & 30 & $20.00 \%$ \\
Pingueculum & 30 & 20.005 \\
Pterygium & 51 & $34.00 \%$ \\
\hline
\end{tabular}

Some respondents suffered from one or more ocular conditions. Table 5 represents a summary of the various ocular conditions; the distribution of some of the conditions per respondents' years of experience in the business environment (thus long-term exposure to sunlight, smoke, heat, and dust) without any form of personal protective equipment is also shown in Table 6.

\section{Discussion}

The study population was entirely made up of females; this is because, unlike many other indigenous industries, the local extraction of palm kernel oil in the Kumasi Metropolis is considered a feminine business.

All of the respondents had one or more ocular symptoms. The widely reported symptom was tearing with the highest prevalence of $73.3 \%$, with the least reported symptom being dizziness $(0.7 \%)$. The high prevalence of tearing could be attributed to the fact that respondents are continually exposed to intense smoky environment which causes ocular irritation that could excite lacrimation.

In a study on eye diseases among kitchen staff in senior high schools in the Kumasi Metropolis [8] by Kumah et al. (2009), tearing was not the widely reported ocular symptom or complaint. The major presenting ocular complaint among the 290 respondents in that study was itchy eyes, with a prevalence of $50.3 \%$ followed by excessive tearing with a prevalence of $43.1 \%$. Just like the palm kernel oil extraction business, all the schools in that study used firewood as the primary source of fuel [8]. A similar study showed an association between eye irritations (tearing) and the use of intense smoke-producing biomass fuel for cooking [9].

Regarding the association between respondents' duration of experience in the business and the reported ocular symptoms, the results apparently showed that those who were new to the business of the kernel oil extraction complained more of acute ocular symptoms such as tearing, itching, and headache but the association was not statically significant $(P>0.05)$. There was, however, an association between blurred vision and longer duration of work experience. Women who had been in the business for a long time period complained significantly of blurred vision $(P<0.05)$; blurred vision was probably due to prolonged exposure to smoke.

However, the results in Table 6, depicting the distribution of eye diseases by the number of years of experience, should be considered in the light of a possible number of challenges to our design. It is possible that the age of the study 
TABLE 6: Distribution of eye diseases by years of experience in business.

\begin{tabular}{|c|c|c|c|c|c|}
\hline \multirow{2}{*}{ Eye disease } & \multicolumn{5}{|c|}{ Years of experience in business } \\
\hline & $1-5(n=37)$ & $6-10(n=35)$ & $11-15(n=31)$ & $>15(n=47)$ & Total $(N=150)$ \\
\hline Conjunctivitis & $4(10.8 \%)$ & $4(11.4 \%)$ & $0(0 \%)$ & $2(4.2 \%)$ & $10(6.7 \%)$ \\
\hline Pterygium & $5(13.5 \%)$ & $10(28.6 \%)$ & $14(45.2 \%)$ & $22(46.8 \%)$ & $51(34.0 \%)$ \\
\hline Pingueculum & $3(8.1 \%)$ & $8(22.8 \%)$ & $5(16.1 \%)$ & $14(29.8 \%)$ & $30(20.0 \%)$ \\
\hline Cataract & $0(0 \%)$ & $2(5.7 \%)$ & $8(25.8 \%)$ & $20(42.5 \%)$ & $30(20.0 \%)$ \\
\hline $\mathrm{AMD}^{*}$ & $0(0 \%)$ & $0(0 \%)$ & $2(6.4 \%)$ & $2(4.2 \%)$ & $4(2.7 \%)$ \\
\hline
\end{tabular}

${ }^{*}$ Age related macular degeneration.

participants as a probable confounder might have accounted for the results shown in Table 6 .

Notwithstanding, in a related study, acute eye symptoms were more frequently reported by wood users who were younger than 28 years of age $(P<0.05)$ than by nonwood users. In that study, a marginally significant difference was observed in older women [10].

The number of respondents with ocular diseases was 84 , giving a prevalence of $56.0 \%$ for ocular diseases among the respondents. Some of the respondents on examination had more than one condition. Pterygium was the most prevalent (34.0\%) eye condition among all of the other conditions detected. In a similar study done in Meskan, southern Ethiopia, the prevalence of pterygium was also high and was found to be $50.0 \%$ [11]. The second highest prevalent ocular diseases found in this study were cataract and pinguecula, each with a prevalence of $20.0 \%$.

The study also reviewed an association between longterm exposure to sunlight, smoke, heat, wind, and dust and the development of cataract, pterygium, and macular degeneration among the participants $(P<0.05)$. A comparable study also showed a strong association between exposure to sunlight and the formation of pterygium; the most striking increase in the risk of pterygium occurred in subjects who worked outdoors (just like the respondents in this study) compared to those who worked indoors $(P<0.05)[12]$.

A total of $18.0 \%$ of blindness caused by cataract may be attributable to biomass fuel (wood, dung, and crop residue) used for cooking [13]. This also translates into $29.0 \%$ of blindness in rural areas and $6.0 \%$ in the urban environment [13].

Researchers also have identified a higher percentage of risk of getting an eye disease among those who never wear eye protection and hat in the sun. The prevalence of pterygium among individuals who never wear eye protection was mentioned as $8.4 \%$ [11].

Eye irritation during cooking was studied in Lusaka, Maputo, and Hanoi in Zambia, Mozambique, and Vietnam, respectively, and found to be associated with use of intense smoke-producing biomass fuel for cooking; the smoke produced is a precursor to the development of conjunctivitis, cataract, pterygium, pinguecula, and macular degeneration [9], which are comparable to the eye conditions found among the population for this study.

\section{Conclusion}

The prevalence of ocular diseases among the women engaged in the local extraction of palm kernel was $56.0 \%$. The ocular disease with the highest prevalence was pterygium, followed by cataract and pinguecula. There was also a high prevalence of ocular diseases among respondents who had longer exposure to the risk factors (smoke, dust, heat, etc.) in the business. The common complaints of those with ocular diseases were tearing and itchiness.

Regular eye examination is recommended since these women are exposed to several risk factors which play important roles in ocular morbidities.

Public education should focus on encouraging participants to take appropriate protective measures, such as wearing sunglasses and brimmed hats when outdoors and face shields during the extraction of kernel oil. Further research is required to help understand the relative contributions of the different risk factors.

Also, the workers should be advised to take frequent breaks during work since continual exposure to smoke emanating from wood fuel can lead to possible (associated) cardiovascular complications. The workers must be educated on facial hygiene since foreign materials settling on the orbital area and on the eyelashes can precipitate conjunctivitis and other inflammatory eye diseases.

\section{Conflict of Interests}

The authors declare that there is no conflict of interests regarding the publication of this paper.

\section{References}

[1] http://dictionary.reference.com/, June 2014.

[2] Occupational and Environmental Hazard, 2014, http://www .birth.com.au/home.

[3] R. Ashaley, S. A. Ewoade, R. Koomson, F. O. Djanm, and A. Acquah, Report on the Hazards Associated with Palm Kernel Oil Production at the 6th Micro Projects at Ada (Koforidua), Eastern Region, Ghana, 2001.

[4] M. A. Anang and K. O. Boadu, "Occupational hazards and environmental health associated with the traditional palm kernel oil extraction method: a case study of the Abura palm 
kernel oil industry in the Central Regional capital, Cape Coast of Ghana," Pelagia Research Library Der Chemica Sinica, vol. 4, no. 2, pp. 114-121, 2013.

[5] Healthy and Safety Executive, A Recipe for Safety: Occupational Health and Safety in Food and Drink Manufacture, 2005.

[6] "Agency for Toxic Substances and Disease Registry," July 2006, http://www.atsdr.cdc.gov/.

[7] A. K. Khurana, Comprehensive Ophthalmology, 4th edition, 2007.

[8] D. B. Kumah, A. O. Oteng Amoako, and H. Amoako, "Eye diseases among kitchen staff in senior high schools in the the Kumasi Metropolis," Journal of the Ghana Science Association, vol. 11, no. 1, pp. 140-147, 2009.

[9] A. Ellegård, "Tears while cooking: An indicator of indoor air pollution and related health effects in developing countries," Environmental Research, vol. 75, no. 1, pp. 12-22, 1997.

[10] IUCN Energy for Sustainable Development, Volume 9 No. 3, Special section on energy and health, 2005.

[11] F. D. Mackenzie, L. W. Hirst, D. Battistutta, and A. Green, "Risk analysis in the development of pterygia," Ophthalmology, vol. 99, no. 7, pp. 1056-1061, 1992.

[12] J. Wlodarczyk, P. Whyte, P. Cockrum, and H. Taylor, "Pterygium in Australia: a cost of illness study," Clinical \& Experimental Ophthalmology, vol. 29, no. 6, pp. 370-375, 2001.

[13] V. K. Mishra, R. D. Retherford, and K. R. Smith, Effects of Cooking Smoke on Prevalence of Blindness in India, Population Series no. 91, 1997. 


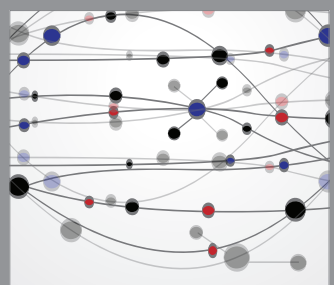

The Scientific World Journal
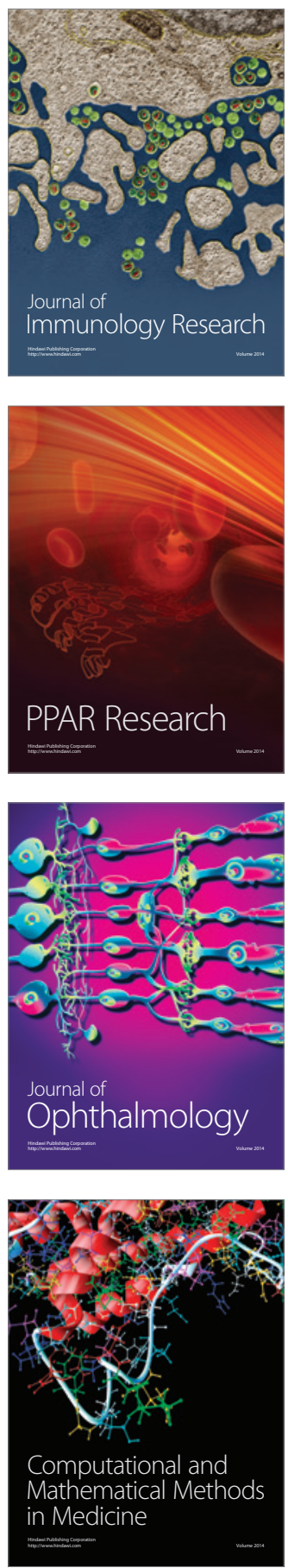

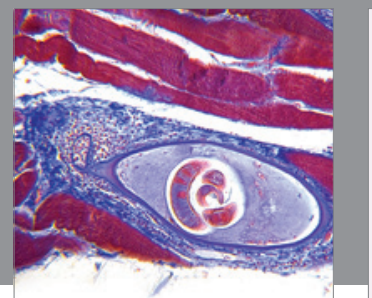

Gastroenterology

Research and Practice
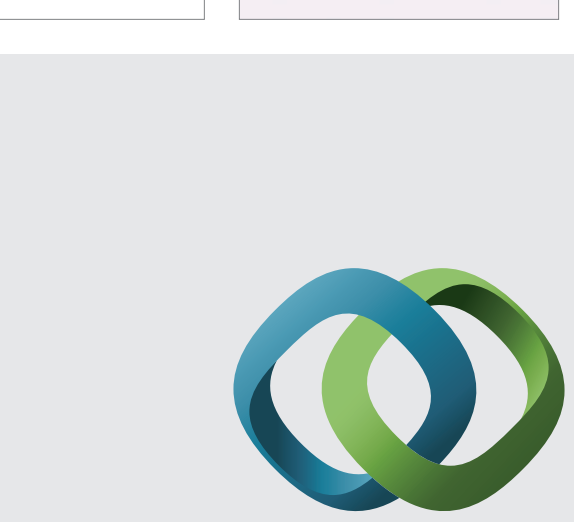

\section{Hindawi}

Submit your manuscripts at

http://www.hindawi.com
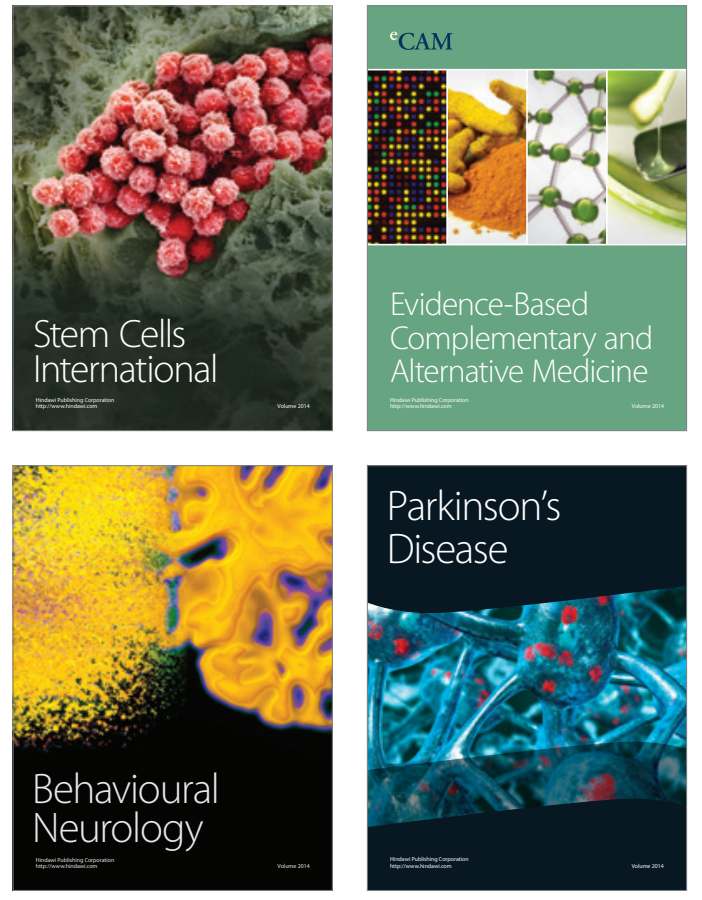
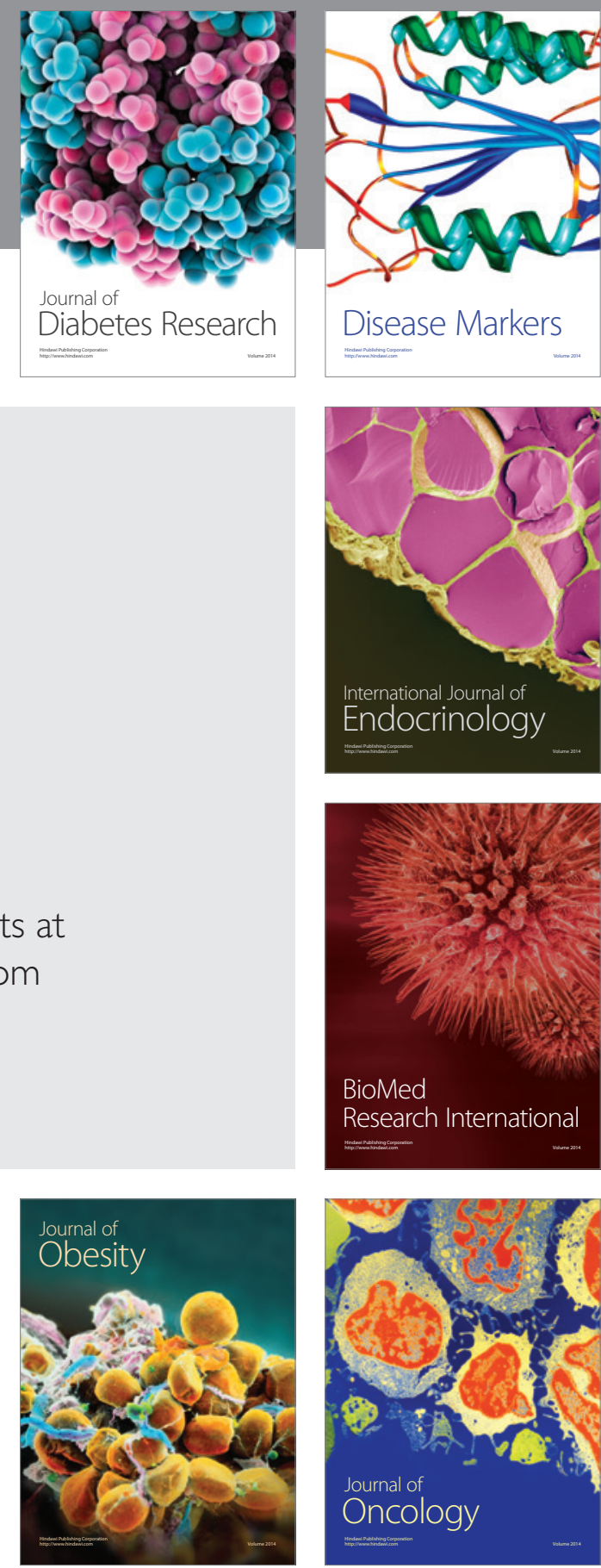

Disease Markers
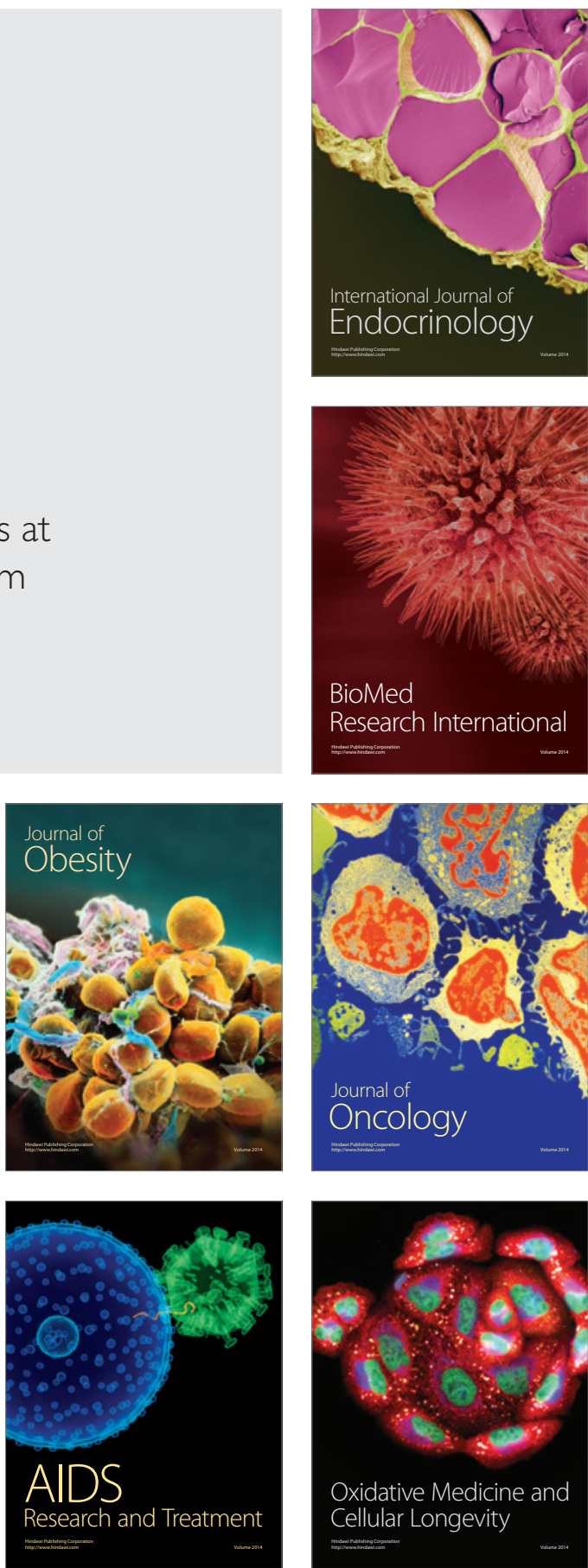